\title{
The Static Analysis of a Porous Aerostatic Bearing
}

\author{
Ming-Fei Chen ${ }^{1}$, Kuo-Yu Chien ${ }^{2}$, Yen-Ting Chen ${ }^{2}$, \\ Chuang-Chin Yang ${ }^{3}$ and Chin-Chia Liu ${ }^{3 *}$
}

\begin{abstract}
A study was made of a porous aerostatic bearing by analysis of its relevant static characteristics. The purpose was to authenticate the theoretical computing results in terms of previously published data. The porous aerostatic bearing and its working mechanism was first introduced after which the mathematical model and the boundary conditions were built. Graphs of the characteristics of the porous aerostatic bearing were made that included data about capacity and clearance and a comparison was made between these findings and the accepted published data to establish and verify correctness of the theory.
\end{abstract}

Keywords-Porous restriction, porous material, aerostatic bearing, finite difference method, orifice restriction.

\section{Introduction}

The continuous development of technology has increased the need for high precision machinery. The characteristics of aerostatic bearing are relevant and important indexes for precision technology. An aerostatic bearing has serious advantages over the normal and commonly used hydrostatic bearing. They can allow higher speeds, greater precision, lower pollution and will have a serious influence on future precision technology.

Reynolds [1] derived a basic lubrication equation for aerostatic bearings, according to hydro mechanical principles and worked out a partial differential equation for pressure, density, relevant velocity and the thickness of the lubricating film. This became the Reynolds equation, which laid down a foundation for liquid lubrication theory. Fuzhang Zhao [2] et al optimized the parameter setting of two types of aerostatic bearing design and Togo Shinichi [3] derived the central finite difference method to calculate the pressure distribution of gas films in various bearings, including static, dynamic and mixed arc gas types.

\section{Ming-Fei Chen}

Department of Mechatronics Engineering, National Changhua University of Education

Taiwan

2. Kuo-Yu Chien, Yen-Ting Chen

Mold \& Precision Machining Technology Section Metal Industries Research $\&$ Development Centre

Taiwan

3. Chuang-Chin Yang, Chin-Chia Liu

Department of Industrial Education and Technology, National Changhua University of Education

Taiwan
Porous bearings, made from porous material, can be metallic or non-metallic. Metallic porous bearings are made by high temperature sintering and the bearings are permeable to air. The porosity is usually between $20 \%$ and $40 \%$ and must be uniform [4] throughout the bearing. Using Darcy's Law, Sheinberg [5] et al derived figures for the flow and incompressibility of liquid through porous material, and conducted the analysis of pressure distribution, bearing capacity, rigidity, etc.

Wenqi Ma et al [6] studied the characteristics of orifice restriction in aerostatic radial bearings and compared this with other methods of restriction. Li Yuntang et al [7] analyzed aerostatic thrust bearings in a quest for the best design parameters.

\section{Basic theoretic structure}

A mathematical model was derived to determine all the different characteristics of porous aerostatic bearings. Simulation analysis was done and Figure 1 shows the details of the aerostatic bearing [8] used in this paper.

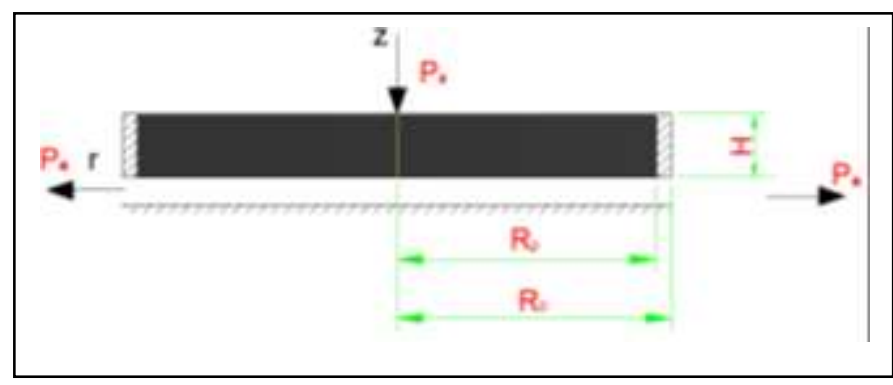

Figure 1. Configuration of the new porous air bearing [8]

$\mathrm{P}_{\mathrm{s}}$ : supply gas pressure. $\mathrm{P}_{\mathrm{a}}$ : atmospheric pressure. $\mathrm{R}_{0}$ : radius of porous bearing. $\mathrm{R}_{\mathrm{p}}$ : radius of porous structure. $\mathrm{H}$ : thickness of porous structure.

\section{A. The Reynolds equation[1]}

To design a gas bearing, all its characteristics, such as bearing capacity, pressure etc, should be known. Pressure distribution can be deduced by the gas lubrication equation as follows:

$$
\frac{\partial}{\partial x}\left(P h^{3} \frac{\partial P}{\partial r}\right)+\frac{\partial}{\partial y}\left(P h^{3} \frac{\partial^{2} P^{2}}{\partial y}\right)=6 \eta\left[U \frac{\partial}{\partial x}(P h)+2 \frac{\partial}{\partial t}(P h)\right]
$$

However, on the left side of the equals sign, the results refer to speed and squeeze film effect. But in this paper, we 
Proc. of The Third Intl. Conf. on Advances in Computing, Control and Networking - ACCN 2015.

Copyright (C) Institute of Research Engineers and Doctors, USA .All rights reserved.

ISBN: 978-1-63248-082-8 doi: 10.15224/ 978-1-63248-082-8-01

only consider stability and used a round flat bearing, so we can ( $x=r, y=r \theta$ ) adapt equation (1) as follows:

$$
\frac{\partial}{\partial r}\left(P h^{3} \frac{\partial P}{\partial r}\right)+\frac{\partial}{\partial r \theta}\left(P h^{3} \frac{\partial^{2} P^{2}}{\partial r \theta}\right)=0
$$

\section{B. Flow equation[3]}

The mass flow at the inlet of a porous gas pressure bearing can be represented by equation (3):

$$
Q_{\text {in }}=\frac{\phi \cdot A\left(P_{s}^{2}-P_{r}^{2}\right)}{2 \cdot \mathfrak{R} \cdot T \cdot \mu \cdot H}
$$

\section{Basic parameter setting}

In this paper the simulation analysis was conducted using Matlab. The relationship diagram of various characteristics of porous aerostatic bearing and pressure distribution within the bearing can be obtained. And its relevant basic parameters are shown in Table I.

TABLE I. BASIC PARAMETERS OF A POROUS BEARING[8].

\begin{tabular}{|l|c|c|}
\hline \multicolumn{1}{|c|}{ Name } & Value & Unit \\
\hline Radius of porous bearing $\left(R_{0}\right)$ & 2.65 & $\mathrm{~cm}$ \\
\hline Thickness of porous structure $(H)$ & 0.6 & $\mathrm{~cm}$ \\
\hline Radius of porous structure $\left(R_{0}\right)$ & 2.5 & $\mathrm{~cm}$ \\
\hline Atmospheric pressure $\left(P_{a}\right)$ & 1.0 & $\mathrm{~kg} / \mathrm{cm}^{2}$ \\
\hline Supply gas pressure $\left(P_{s}\right)$ & 5.5 & $\mathrm{~kg} / \mathrm{cm}^{2}$ \\
\hline Absolute temperature $\left(T^{\circ}\right)$ & 288 & $\mathrm{~K}$ \\
\hline Atmospheric constant $(R)$ & 2927 & $\mathrm{~cm} / \mathrm{K}$ \\
\hline $\begin{array}{l}\text { Air permeability of porous } \\
\text { material }(\psi)\end{array}$ & $5.69 \times 10^{-12}$ & $\mathrm{~cm}$ \\
\hline Air density $\left(\rho_{\mathrm{a}}\right)$ & $1.31 \times 10^{-7}$ & $\mathrm{~kg} / \mathrm{cm}^{3}$ \\
\hline Gas specific weight $(\gamma)$ & $1.226 \times 10^{-5}$ & $\mathrm{~kg} / \mathrm{cm}^{3}$ \\
\hline
\end{tabular}

A flow diagram of the procedures used for calculating the porous aerostatic bearing data is shown in Figure 2.

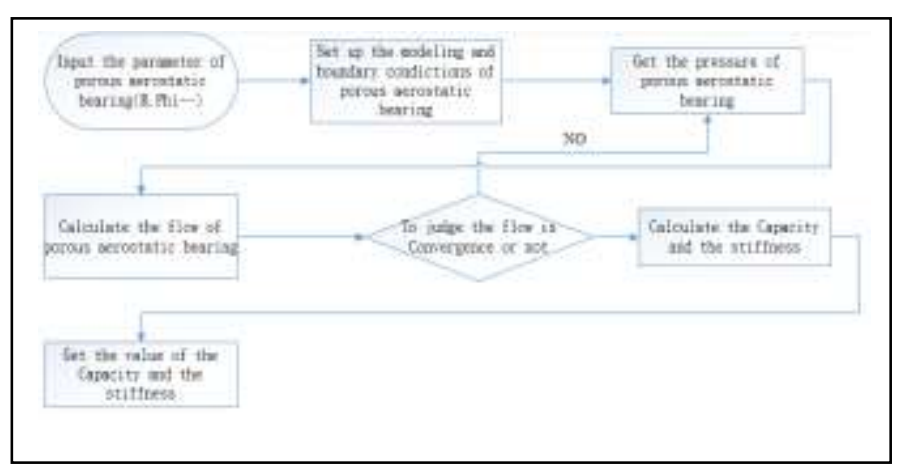

Figure 2. Procedures used for calculating porous aerostatic bearing data.

\section{Verifying the correctness of the equation}

After the program had been coded, its correctness also needed to be verified, so the simulation results were compared to those in the literature [9]. Table II shows the basic parameters as previously published in the literature.

TABLE II. BASIC PARAMETERS FOR POROUS AEROSTATIC BEARINGS FROM THE LITERATURE[9].

\begin{tabular}{|l|c|c|}
\hline \multicolumn{1}{|c|}{ Name } & Value & Unit \\
\hline Radius of porous bearing $\left(R_{0}\right)$ & 2.5 & $\mathrm{~cm}$ \\
\hline Thickness of porous structure $(H)$ & 0.5 & $\mathrm{~cm}$ \\
\hline Radius of porous structure $\left(R_{0}\right)$ & 2.25 & $\mathrm{~cm}$ \\
\hline Atmospheric pressure $\left(P_{a}\right)$ & 1.0 & $\mathrm{~kg} / \mathrm{cm}^{2}$ \\
\hline Supply gas pressure $\left(P_{s}\right)$ & 5.0 & $\mathrm{~kg} / \mathrm{cm}^{2}$ \\
\hline Absolute temperature $\left(T^{\circ}\right)$ & 293 & $\mathrm{~K}$ \\
\hline Atmospheric constant $(R)$ & 2927 & $\mathrm{~cm} / \mathrm{K}$ \\
\hline $\begin{array}{l}\text { Air permeability of porous } \\
\text { material }(\psi)\end{array}$ & $7.95 \times 10^{-15}$ & $\mathrm{~cm}$ \\
\hline Air density $\left(\rho_{\mathrm{a}}\right)$ & $1.31 \times 10^{-7}$ & $\mathrm{~kg} / \mathrm{cm}^{3}$ \\
\hline Gas specific weight $(\gamma)$ & $1.226 \times 10^{-5}$ & $\mathrm{~kg} / \mathrm{cm}^{3}$ \\
\hline
\end{tabular}

Figures 3 and 4 are comparisons between published data from the literature and the simulation figures for bearing capacity and rigidity obtained in this study using the same supply gas pressure in both cases.

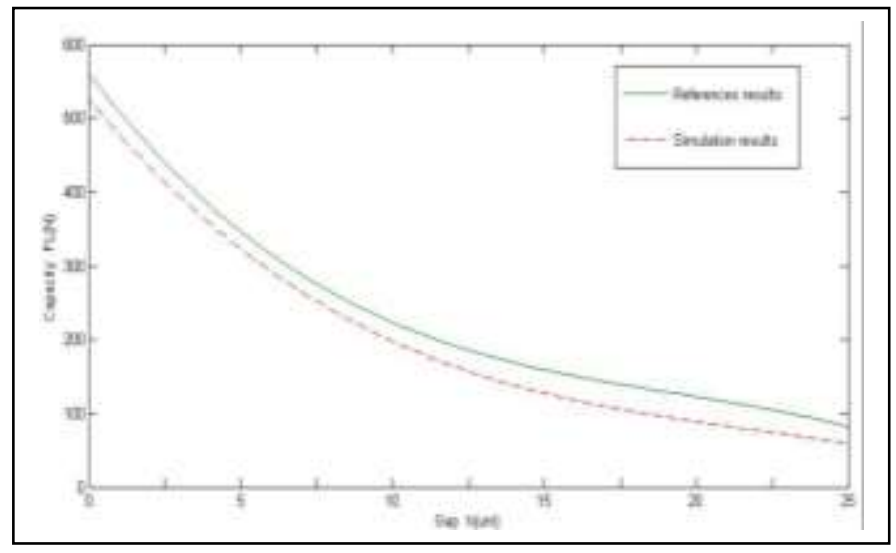

Figure 3. Bearing capacity to clearance relationship comparison diagram [9] with supply gas pressure of $5 \mathrm{~kg} / \mathrm{cm}^{2}$. 
Proc. of The Third Intl. Conf. on Advances in Computing, Control and Networking - ACCN 2015.

Copyright (C) Institute of Research Engineers and Doctors, USA .All rights reserved.

ISBN: 978-1-63248-082-8 doi: 10.15224/ 978-1-63248-082-8-01

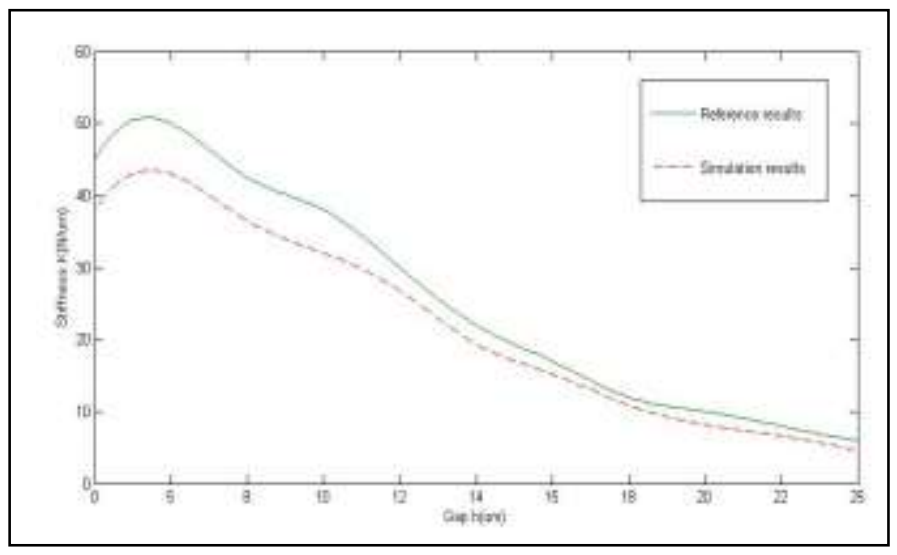

Figure 4. Bearing rigidity to clearance relationship comparison diagram [9] with supply gas pressure of $5 \mathrm{~kg} / \mathrm{cm}^{2}$.

As shown in Figure 3, when the clearance is $5 \mu \mathrm{m}$ the bearing capacity as given in the literature is $342 \mathrm{~N}$, and that of the simulation is $321 \mathrm{~N}$, the difference being $6.14 \%$. With other clearance values the maximum error value is $18 \%$. The reason for these differences may be that the method used for the analysis itself is different. However, further analysis revealed that the higher the supply gas pressure the lower the error.

From Figure 4 it can be seen that in both the literature and simulation values the maximum rigidity of $50 \mathrm{~N} / \mu \mathrm{m}$ and $43 \mathrm{~N} / \mu \mathrm{m}$ is reached with a clearance of $5 \mu \mathrm{m}$. In Figure 3 and 4 we can also see that the trend in both the literature values and the simulation results are quite similar, so the correctness of the program code used in this study is validated.

\section{A. Analysis of the static characteristics of a porous aerostatic bearing}

After validating the correctness of the porous aerostatic bearing program, a simulation was conducted according to the parameters given in Table I and the relationship diagram of various characteristics is shown in Figure 5.

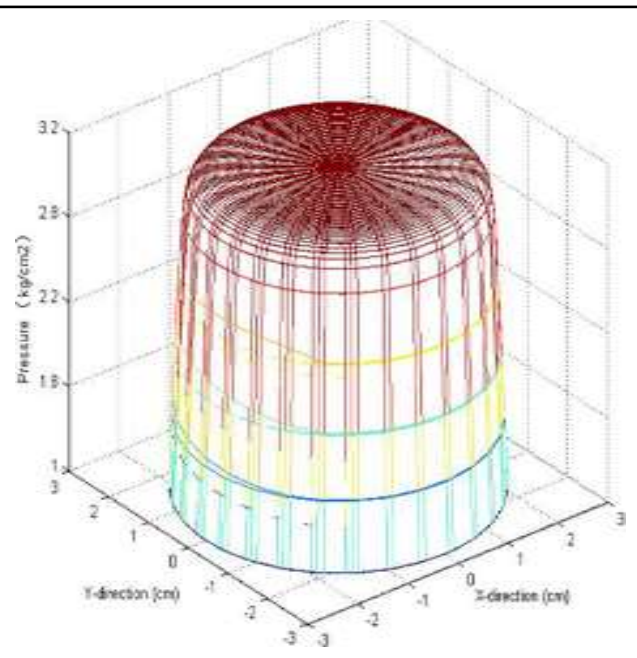

Figure 5. The pressure distribution situation [8] with a supply gas pressure of $5.5 \mathrm{~kg} / \mathrm{cm}^{2}$.

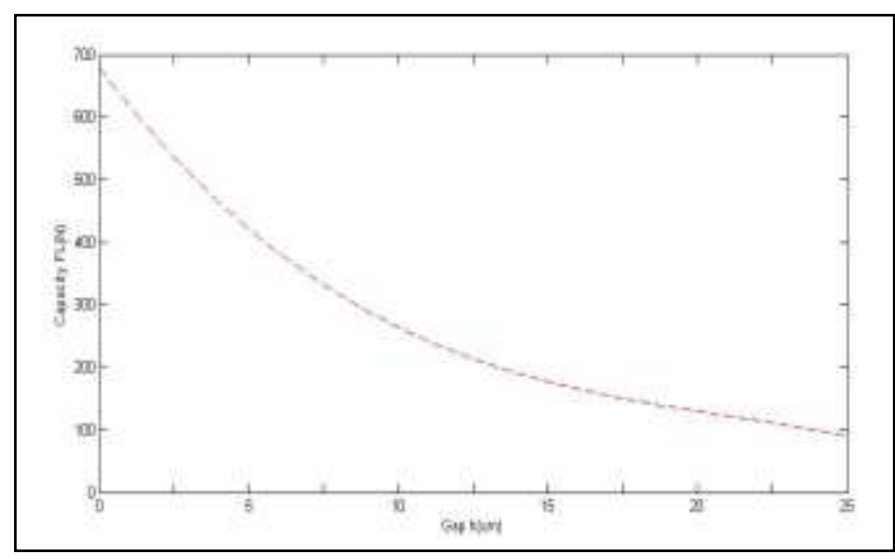

Figure 6 . The bearing capacity to clearance relationship diagram [8] with a supply gas pressure of $5.5 \mathrm{~kg} / \mathrm{cm}^{2}$.

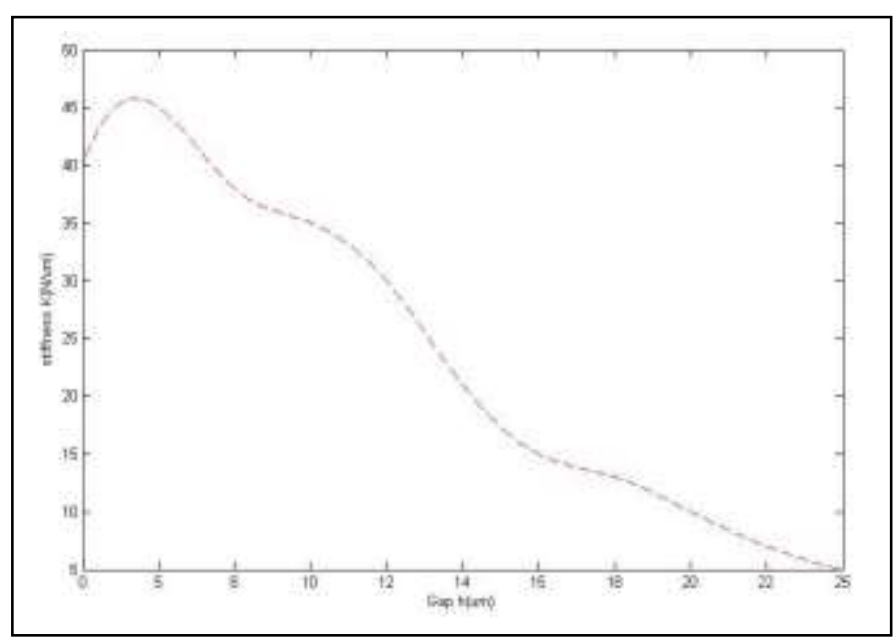

Figure 7. The rigidity to clearance relationship diagram [8] with a supply gas pressure of $5.5 \mathrm{~kg} / \mathrm{cm}^{2}$.

From the pressure distribution situation, as shown in Figure 5, we can see that the pressure value from the simulation program is $3.18 \mathrm{~kg} / \mathrm{cm} 2$ and from Figure 6 we can see that when the supply gas pressure is $5.5 \mathrm{~kg} / \mathrm{cm} 2$ and the clearance $5 \mu \mathrm{m}$, the bearing capacity is $450 \mathrm{~N}$. In Figure 7 it can be seen that maximum rigidity of $45 \mathrm{~N} / \mu \mathrm{m}$ is reached when the clearance is $7 \mu \mathrm{m}$, and the gas pressure is $5.5 \mathrm{~kg} / \mathrm{cm} 2$.

\section{CONCLUSION}

The results of this simulation study on porous aerostatic bearings have an error value of between 6 and $18 \%$ when compared to published values. However the trends of bearing capacity and rigidity are very similar as can be clearly seen in the graphs. The program code used in this study will definitely be of value in an initial stage of bearing design.

\section{References}

[1] O Reynolds. On the Theory of Lubrication and Its Application to $\mathrm{Mr}$ Beauchamp Tower's Experiments, Including an Experimental Determination of the Viscosity of Olive Oil (1886) vol. 177. 
Proc. of The Third Intl. Conf. on Advances in Computing, Control and Networking - ACCN 2015.

Copyright (C) Institute of Research Engineers and Doctors, USA .All rights reserved.

ISBN: 978-1-63248-082-8 doi: 10.15224/ 978-1-63248-082-8-01

[2] Fuzhang Zhao and Clarence A Andersson. Air Bearing Design Optimization. Advanced Materials Division, M Cubed Technologies, Inc, Newark, DE 19711.

[3] Sogo Jin ichi. Gas bearing from design to manufacture. Fu Han Publishing house (1985).

[4] T H Panzera, J C Rubio, C R Bowen, P J Walker. Micro-structural design of materials for aerostatic bearings, Cement \& Concrete Composites, vol. 30, 2008, pp. 649-660.

[5] S A Sheinberg and V G Shuster. Resistance to Vibration of Hydrostatic Thrust Bearings. Machine Tool (1960) 24-291.

[6] Wenqi Ma, Hechun Yu, Zuwen Wang, Longxing Chen, Haiyan Liu, Research on Characteristics of Orifice Type Radial Aerostatic Bearings under High-speed Conditions.

[7] Li Yuntang, Ding Han, Performance Analysis of Aerostatic Thrust Bearings with Inherently or Pocketed Orifice Restrictor. Third International Conference on Measuring Technology and Mechatronics Automation, (2011).

[8] Kuo-Yu Chien, Chung-Li Tsai. Development of a Planar Porous Aerostatic Bearing with Dual Restrictive Layer.

[9] Wu Dingzhu, Tao Jizhong. Analysis of Static Performance of Porous Graphite Aerostatic Thrust Bearings (2010). 